\title{
THE IMPACT OF PROGRAM STRUCTURE AND GOAL SETTING ON MENTORS' PERCEPTIONS OF PEER MENTORSHIP IN ACADEMIA
}

\begin{tabular}{c|c|c|c} 
ZEESHAN HAQQEE & LORI GOFF & KRIS KNORR & MICHAEL B. GILL \\
MCMASTER UNIVERSITY & MCMASTER UNIVERSITY & MCMASTER UNIVERSITY & MCMASTER UNIVERSITY
\end{tabular}

\begin{abstract}
Many peer mentorship programs in academia train senior students to guide groups of incoming students through the rigors of postsecondary education. The mentorship program's structure can influence how mentors develop from this experience. Here, we compare how two different peer mentorship programs have shaped mentors' experiences and development. The curricular peer mentorship program was offered to mentors and mentees as credited academic courses. The non-curricular program was offered as a voluntary student union service to students and peer mentors. Both groups of peer mentors shared similar benefits, with curricular peer mentors (CMs) greatly valuing student interaction, and non-curricular peer mentors (NCMs) greatly valuing leadership development. Lack of autonomy and lack of mentee commitment were cited as the biggest concerns for CMs and NCMs, respectively. Both groups valued goal setting in shaping their mentorship development, but CMs raised concerns about its overemphasis. Implications for optimal structuring of academic mentorship programs are discussed. Keywords: peer mentorship, goal setting, postsecondary education, training program, program structure, student development
\end{abstract}

\section{Résumé}

Dans le milieu universitaire, de nombreux programmes de mentorat par les pairs forment des étudiants avancés pour aider des groupes d'étudiants de première année à faire face aux exigences de l'enseignement supérieur. La structure du programme de mentorat peut déterminer la manière dont les mentors se développent à partir de cette expérience. Nous comparons ici la contribution de deux types de programmes de mentorat à l'expérience et au parcours des mentors. Un des programmes de mentorat a été proposé aux mentors et aux mentorés en tant que cours universitaire crédité. Un autre programme de mentorat, non curriculaire, a été proposé aux mentors et aux mentorés en tant que volontariat dans le cadre de l'association étudiante. Les deux groupes de mentors ont indiqué des avantages similaires, les mentors du programme académique accordant une grande importance à l'interaction avec les mentorés, et les mentors du programme non académique accordant une grande importance au développement du leadership. En revanche, les mentors ont relevé un manque d'autonomie des mentorés dans le cadre du mentorat académique, et un manque d'engagement dans le cadre du mentorat non académique. Les deux groupes ont apprécié l'établissement d'objectifs pour le développement de leur mentorat, mais les mentors du programme académique ont exprimé des inquiétudes quant à l'importance excessive accordée à cette question. Les implications pour une restructuration optimale des programmes de mentorat académique sont discutées.

Mots-clés : mentorat par les pairs, établissement d'objectifs, études postsecondaires, programme de formation, structure de programme, développement des étudiants

\section{Introduction}

Navigating life transitions can be difficult and there is no exception to the transition that students face when they enter postsecondary programs. Academic persistence and success in postsecondary education has been well documented in the literature and often determined by factors such as academic skill, knowledge, motivation, involvement, connectedness, and more. (Astin, 1975; McKenzie \& Schweitzer, 2001; Tinto, 1975, 1997; Venezia \& Jaeger, 2013). Peer mentorship programs offer a way to support this transition by pairing incoming students with senior students who guide the new student 
through the same obstacles the senior students faced in their own first year (Crisp \& Cruz, 2009; Jacobi, 1991; Pugliese et al., 2015; Rodger \& Tremblay, 2003; Salinitri, 2005). With the support of their peer mentors, students can develop useful attributes, such as improved time management skills and a sense of responsibility (McLean, 2004), as well as increased self-esteem and sense of satisfaction with their postsecondary program (Ferrari, 2004; Yomtov et al., 2017).

Peer mentors also benefit from engaging in a peer mentoring relationship. They greatly value the opportunity to help and connect with their mentees, as well as develop friendships with other students in their program (Colvin \& Ashman, 2010). While peer mentorship is not without some risk, such as an underwhelming commitment from the mentee, or the pressure on a mentor to be an infallible role model, the benefits generally outweigh the risks (Beltman \& Schaeben, 2012; Collings et al., 2014; Colvin \& Ashman, 2010; Pugliese et al., 2015). Other benefits for peer mentors include stimulating self-reflection and being able to reapply the fundamental skills they picked up from their previous experiences; skills which they may have thought were forgotten (Beltman \& Schaeben, 2012; Colvin \& Ashman, 2010).

\section{The Impact of Program Structure on Peer Mentorship}

Peer mentorship programs are typically responsible for organizing mentor-mentee relationships and educating their members on the process of mentorship. These mentorship programs can vary in the degree to which they formalize structure within their programs. High-structured programs may involve formal training, planned activities, and periodic evaluation of the mentors' progress, whereas low-structured programs may involve less rigorous or informal training and fewer scheduled activities, while allowing more freedom in how mentors interact with their mentees (James et al., 2015).

The level of structure in a mentorship program can influence the form of training mentors receive. The effectiveness of this training plays a critical role in shaping the mentor's efficiency and overall performance (Bryant \& Terborg, 2008; Leidenfrost et al., 2014; Scandura \& Williams, 2002). If training programs do not adequately prepare mentors for their duties, mentors can be left feeling confused about their responsibilities in the pro- gram-they may lack an understanding of their role in mentorship and may struggle to properly handle challenging situations (Eby \& Lockwood, 2005; Gibb, 1999; Quesnel et al., 2012). A precise understanding of what good mentorship should look and feel like would help mentors set realistic expectations for themselves, leading to a more rewarding feeling for successful mentorship (Eby et al., 2006). On the other hand, having too much structure and heavily mandating mentorship program duties can have drawbacks on the quality of a mentor's performance. Mandated mentorship programs are at risk of stressing the mentors with added responsibility in their lives, leading to feelings of indifference about mentorship (Boyatzis et al., 2006).

Less research has been conducted that compares or reviews the aspect of program structure of peer mentorship programs involving junior and senior students at an undergraduate institution. While the importance of peer mentorship programs to the satisfaction of mentors' perception of mentorship has been studied (Heirdsfield et al., 2008), it is less clear which structures and components of such programs influence mentors' perceptions and development. Examples of components to consider include whether a mentorship program is voluntary, required, or based on incentive such as financial or academic credit. Peer mentors can vary greatly on their motivations to mentor. Some incentives include increased opportunity to network and interact with like-minded mentees, as well as a positive sense of accomplishment for having helped another person (Allen, 2003; Beltman \& Schaeben, 2012; Du Preez et al., 2013).

\section{The Impact of Goal Setting on Peer Mentorship}

Goal setting is another component common to peer mentorship programs (Parise \& Forret, 2008; Sorrentino, 2006). As part of their formal training, mentors are often encouraged to set goals on what they strive to gain from their mentorship experience. Active goal setting aims to help the mentor achieve some sort of useful change in their life, on either an academic, professional, or personal level. By giving them something to work toward, goal setting also ensures that mentors keep their attention on goal-relevant activities, and away from goal-irrelevant activities, allowing for more focused and productive mentorship experiences (Locke \& Latham, 2002). How- 
ever, implementation of goal setting in a peer mentorship program should ensure that it impacts mentors positively (Locke \& Latham, 2002). For instance, the goals being set should be realistically challenging-enough to ensure an effortful and committed contribution from the mentor, without being so ambitious as to risk failure and disappointment (Zachary \& Fischler, 2011).

\section{Conceptual Framework}

Indeed, several conceptual frameworks exist to help us explore goal setting and its impact on mentorship. In the field of education, however, the concept of constructive alignment has had significant impact on the ways that postsecondary educators design lectures, courses, and programs (Biggs \& Tang, 2003). This is largely due to the elegant simplicity of the model and the relative ease of implementation. Biggs states that constructive alignment for effective learning begins with an outcomes-based approach, and that "teaching and assessment methods are then designed to best achieve those outcomes" (Biggs, 2014, p. 5). Goal setting for mentors can be set up in a similar approach. That is, they may begin with a well-defined and measurable mentoring goal or outcome, and then identify a plan for working toward that goal, analogous to the teaching and learning activities described by Biggs. Finally, mentors can collect evidence to determine their progress, or the degree to which they have achieved their goals, analogous to "assessment" in Biggs's framework (Biggs, 2014, p. 5).

Several researchers have found that active goal setting is indeed influential in helping students improve upon desired skills and academic performance (e.g., Komarraju \& Nadler, 2013; Martin \& Elliot, 2016; Parise \& Forret, 2008; Sorrentino, 2006; Zimmerman et al., 1992). However, there is little research on the effectiveness of active goal setting for mentors in peer mentorship programs, particularly with helping mentors improve themselves to maximize their mentorship experience. In one formal training program, mentors strongly desired implementing goal setting as part of their training (Parise \& Forret, 2008); however, it is unclear whether mandating goal setting in mentorship programs would benefit mentors in training. One must also consider voluntary participation versus credit or incentive-based programs, and how motivations between these two groups could lead to different experiences in mentorship entirely.

\section{The Current Study}

The purpose of this study was to compare mentors' experiences in peer mentorship from two differently structured mentorship programs. Specifically, we aimed to establish whether mentors' expectations and impressions of peer mentorship would differ based on the structure of their training program and the type and extent of training they underwent. We explored whether mentors' expectations and impressions of their peer mentorship program were met, whether they gained any benefits or faced any challenges during their mentorship experience, as well as how goal setting influenced how they developed as mentors. Additionally, we were interested in whether taking a mandated and evaluated approach to goal setting would either help or hinder mentors' experiences on mentorship. This research will also contribute to the literature on peer mentorship programs in postsecondary institutions.

\section{Institutional and Mentoring Context}

In this study, we compared the peer mentors' experiences between two different mentorship programs offered at McMaster University, a medium-sized (approximately 28,000 full-time undergraduate students, $87 \%$ of which are domestic), research-intensive institution in Hamilton, ON, Canada. McMaster has been implementing localized peer mentorship programs within its faculties for at least 20 years. A centralized pan-university mentorship program was launched in 2014. One peer mentorship program that we studied was offered within the Faculty of Science as a credit-based elective that upper-year Science students could take as part of their curriculum, while the second peer mentorship program was offered as a pan-university service through the undergraduate student union. The mentors from these two groups will be referred to as curricular peer mentors (CMs) and non-curricular peer mentors (NCMs), respectively.

\section{The Curricular Peer Mentorship Group: The Peer Mentoring in Science Program}

The Peer Mentoring in Science course was designed as an upper-year companion course to a first-year foundational science course. In the first-year course, new university students were exposed to a variety of scientific departments and disciplines and were introduced to several skills that would enhance their ability to succeed as 
students in the Faculty of Science, McMaster's largest Faculty that serves over 7,000 graduate and undergraduate students.

In the 2015 cohort, the first-year science course was comprised of approximately 300 enrolled students, divided into tutorial sections of approximately 25 students. Eleven groups of three peer mentors (CMs) were enrolled in the Peer Mentoring in Science course and facilitated each of these tutorial sections. Peer mentors were between 20 and 22 years old and attending either their third or fourth year of university. This mentorship program ran in the fall semester only, when the new cohort of first-year students began their studies. It is an example of a structured mentorship program that trained its mentors through a goal-setting approach while they mentored the first-year science students. CMs met with their instructors once per week in a 3-hour evening class. During class time, the instructors supervised the mentorship program, while instructing the CMs in approaches to mentoring and facilitation, teaching how to define and achieve personal learning goals in relation to mentoring and leadership, and encouraging development as reflective science mentor practitioners. Assessments in this course included bi-weekly reflective assignments, the development of a mentoring philosophy statement, and a portfolio on mentoring development. This portfolio served as evidence for both their development as mentors and their achievement of their personal mentoring goals.

In addition to the in-class learning and training, each mentoring group met with their assigned first-year tutorial section two or three times per week for 50-minutes sessions. Approximately half of these tutorials were dedicated to facilitating learning activities around various scientific disciplines, which served to teach the firstyear students the skills necessary to succeed in their faculty (termed mini-research investigations or MRIs). The remaining tutorials allowed the CMs to engage with the first-year students as they best saw fit. For example, early in the semester, CMs would design sessions on effective transitions to university and establishing good study skills and habits. Later in the semester, CMs spent time on topics such as managing stress in university and how to select programs for students' second year.

\section{The Non-Curricular Peer Mentorship Group: The Spark Transition and Mentorship Program}

The Spark Transition and Mentorship Program was conceptualized in 2014 by the Student Union's Vice-President of Education. Designed to be a formal, group-based peer mentorship program, it launched during the 20142015 academic term.

The program was developed with the intention to help first-year students develop a sense of comfort and social support within the McMaster community, to foster an appreciation for the value inherent to goal setting and inspire agency in personal development, to hone and practice reflective skills, and to improve awareness of extracurricular opportunities and campus services.

Forty upper year students were selected as Spark Team Leaders, or as we refer to in this paper as non-curricular peer mentors (NCMs), to actively support approximately 580 first-year students. Pairs of mentors were each connected with two groups of 12-16 first-year students: one for the fall semester, and one for the winter semester. Each peer mentoring group met weekly to complete a set of activities organized around particular learning objectives designed to improve student success within university. The ten designed sessions focused on tangible academic skill development (e.g., midterms and study habits, time management and organization, and teamwork), social integration (e.g., self-discovery, getting involved, diversity, and discovering the local community), and personal habits and development (e.g., wellness, compromises and comfort, and life after Spark). Students remained in the program for the duration of one academic term. NCMs committed to maintain informal mentorship relationships outside of the formal sessions and beyond the completion of the program.

Although NCMs guided their mentees in setting goals to assist in personal and academic development, the Spark program did not formally encourage the NCMs to set any mentorship goals for themselves. Furthermore, while NCMs were provided both written instruction and training on a set of activities relevant to each session, they had the autonomy to determine the specific activities to implement for their group. As such, the Spark program is an example of a less-structured peer mentorship program that did not formally train its mentors through a goal-setting approach. 


\section{Methods}

\section{Research Design and Survey Instrument}

A survey research design was selected to gather information on the experiences of the peer mentors in the two mentorship programs (Jann \& Hinz, 2016; Neuman, 2000). The survey consisted of 19 questions, including both Likert-style and short answer questions regarding mentors' perceptions of their mentorship experiences, which included thoughts on their peer mentorship program, their mentor-led sessions, interactions with mentees, the impact of goal setting on their experiences, the skills that they gained through the process, and the skills that they fostered in their mentees. Likert-scale questions were presented with 5-point or 7-point response scales, each prompting a written, qualitative narrative to describe their Likert scale response choice. Several open ended, narrative-style questions were asked, as well. Some examples of the survey questions appear below (where "program" refers to the mentorship program the peer mentor belonged to):

"On a scale of 1 to 7 , with 1 being the worst and 7 the best, how USEFUL do you think [program] has been to mentors?"

Options available: " 1 = Extremely Unhelpful; 2 = Very Unhelpful; $3=$ Fairly Unhelpful; $4=$ Neither Useful nor Unhelpful; 5 = Fairly Useful; 6 = Very Useful; 7 = Extremely Useful"

The purpose of this question was to gain general insight on the positive aspects of their mentorship experience.

"Which component of [program] do you think has been the most enjoyable to mentors, and why?"

The purpose of this question was to probe mentors' responses on the most positive aspects of their mentorship experience and gain insight into specific benefits tied to their program. This question works in addition to the previous Likert question as it targets specific insight into any positive experiences from mentors despite potentially negative experiences rated overall.
"Which component of [program] do you think mentors view as the one that has the most room for improvement, and why?"

The purpose of this question was to probe mentors' responses on the negative aspects of their mentorship experience and gain insight into specific challenges tied to their program. This question works in addition to the similarly phrased Likert questions as it targets specific insight into any negative experiences from mentors despite potentially positive experiences rated overall.

\section{Participants and Data Collection}

At the end of their mentoring programs, all CMs and NCMs were invited by email to participate in an online survey. Survey data were collected using an open-source, locally hosted, online survey tool (LimeSurvey) in December 2015 after receiving ethics clearance from the McMaster Research Ethics Board. CMs were asked to complete the survey online at the end of their final mentorship class. NCMs were sent an e-mail in February 2016 inviting them to complete the survey within a two-week time window. A single reminder e-mail was sent to the students one week after the initial e-mail. A total of 23 out of $33 \mathrm{CMs}$ and 9 out of 40 NCMs participated in the survey.

\section{Data Analysis}

Likert data was expressed as a percentage response per mentorship group (i.e., total number of either $\mathrm{CM}$ or NCM participants) for each response choice available on the 5- and 7-point scales. Qualitative survey data were extracted and imported into ATLAS-Ti for coding. Open coding was performed using inductive analysis (Lincoln \& Guba, 1985). Data were analyzed, and themes and codes were developed and assigned to individual responses (Freeman, 1998). To avoid issues relating to inter-rater reliability, coding was completed by a single coder, who met with the research group on a weekly basis to review the validity of any themes that were identified. Codes were initially created under broad a priori categories (Freeman, 1998); such as benefits and challenges, and then developed into subcategories such as relating to leadership development or affecting team dynamics. Responses were further organized as originating either from CMs or NCMs. 


\section{Credibility of the Study}

Qualitative validity in this study was established through confirmability, or "the degree to which the results could be confirmed or corroborated by others" (Trochim \& Donnelly, 2007, p. 149). Specifically, survey data were reviewed by the authors multiple times to ensure that each code fit into its best representative category, avoiding redundant or repeated codes that fit under a similar theme. Quotes from the responses were then grouped together by their representative code, tallied, and sorted under the broad categories of benefits, challenges, and goal setting.

\section{Results and Discussion}

Based on our initial thematic analysis, we identified three broad themes in mentors' responses. Here, we first explore mentors' expectations of their mentorship experience. Second, we assess and contrast the benefits and challenges faced by peer mentors from each mentorship group. Finally, we compare mentors' approaches to goal setting between the two groups.

\section{Mentors' Expectations}

To determine the extent to which mentors' expectations were met within their respective peer mentorship groups, we asked mentors of their overall impression of their mentorship program, compared to what they expected when they first began.

\section{Curricular Peer Mentors' Expectations}

Most CMs (17/21; 81\%) stated that their mentorship program met or exceeded their expectations. The opportunity for direct student interaction and the mentees' receptiveness to their peer mentors' advice were cited as invaluable experiences by several peer mentors in the course. Regular self-reflection of mentoring abilities and the opportunity to develop one's leadership and communication skills were also greatly valued in this peer mentorship course. "I didn't expect the mentees to be so receptive to our mentoring. They actively sought our advice and that was more than I expected. Also, I got a lot more responsibility with the mentees which I really enjoyed." (CM \#10)

Some CMs $(4 / 21 ; 19 \%)$ stated that the peer mentorship program did not meet their expectations.
These mentors did not believe that the class had a positive influence on their mentorship experience, stating that few concepts learned from class were transferrable to mentoring in tutorial-led sessions. One mentor believed that there was not enough creative freedom when running MRI sessions. These mentors also felt that their written assignments were unclear and did not reflect their practical development in peer mentorship. Concerns regarding assessment of progress were also echoed from a subset of peer mentors that believed that the course met or exceeded their expectations:

I think this course had a lot of potential and students were really looking forward to it but the lack of understanding of the assignments and the confusion about what is expected of them made it somewhat disappointing. There should be a more clear picture of what is being gained from the course. ( $\mathrm{CM} \# 12$ )

\section{Non-Curricular Peer Mentors' Expectations}

When asked how much peer mentors believed they gained from their mentorship experience compared to what they expected, all nine NCMs stated that the Spark peer mentorship program either met or exceeded their expectations. There were no explicit concerns stated from any of the respondents, but some elaborated that their expectations for their program were initially high, and that these expectations were met by the end of the program. Some NCMs stated that the program was a great opportunity to participate in a leadership initiative, and that Spark had pushed them to become more engaged to and develop quick friendships within the McMaster community. "I imagined Spark to help me grow as a person in certain ways, and give me an opportunity to act as a mentor and give back, and I feel like my expectations have been met." (NCM \#14)

\section{Discussion: Examining Experiences Between Mentorship Groups}

These initial results indicate that both peer mentorship programs have satisfied the expectations of most of their peer mentorship students. It is also apparent that CMs were more open to voicing their concerns for progress evaluation than were NCMs. This is a reasonable expectation when considering that CMs' evaluations would affect their university grade point average, whereas NCMs' progress evaluation would not. We also begin to see that 
CMs' responses appear to focus on the development of their mentorship traits and abilities, whereas NCMs' responses focus more on the development of leadership traits and personal connections.

\section{Peer Mentors' Perceptions of Benefits and Challenges in Peer Mentorship}

To gain a more thorough understanding of peer mentors' perceptions of their mentorship experience, we also asked peer mentors how they felt they benefited from this experience (see Table 1), as well as what they found most challenging (see Table 2).

\section{Benefits Reported by Curricular Peer Mentors}

When asked what peer mentors most appreciated about their mentorship experience, most CMs cited enjoyment in student interaction and building relationships with their mentees. Having a sense of responsibility and leadership for their mentees and receiving positive feedback from them made CMs feel appreciated during tutorial sessions:

I appreciate their appreciation for my tips, tricks, and advice! I also appreciate their enthusiasm and fresh approach to studying. It's easy to get bogged down with work as a third/fourth year student, seeing some fresh faces and new energy is refreshing! (CM \#19)

The chance to connect with these students and have a meaningful and positive impact on their education left CMs feeling rewarded for their efforts. CMs' strong appreciation for student interaction may relate to why CMs also appreciated the opportunity to plan and lead their own tutorial sessions. Running their own tutorials helped CMs develop confidence in their public speaking skills and gave them insight on teaching in a classroom setting. Furthermore, sharing past experiences during discussions allowed CMs to connect with their mentees at a more personal level. These engaging conversations were frequently cited as being the highlight of most CMs mentorship experience.

Having the opportunity to actually run our own tutorials was fantastic. It actually allowed us to use what we were learning in class and apply them to our students. We found that the students enjoyed the peer-run tu- torials the most because they were catered towards our class's strengths and interests. They also allowed us to get valuable feedback on how students liked and disliked the course. I really loved being able to engage in conversations with the students. We often veered off course during the MRIs with the purpose of facilitating discussion that the students were actually interested in - most of it having to do with real life applications of MRI concepts. (CM \#17)

\section{Benefits Reported by Non-Curricular Peer Mentors}

NCMs enjoyed some of the same benefits from their mentorship experience as $\mathrm{CMs}$, such as building relations with other students. Interacting with junior students created a sense of community between junior students and their NCMs, who enjoyed observing their mentees' growth.

Getting to know and see our students mature and evolve over the course of the semester is probably the most enjoyable and exciting. I don't believe spark exists to make future [Team Leaders] out of every student that comes in but rather challenges them a little out of their comfort zone. When very reserved students speak out in group discussion, mentions joining a club on campus, little victories like that make Spark very enjoyable. (NCM \#18)

The most cited benefit among NCMs was the development of leadership skills. Most NCMs surveyed believed that the Spark program helped them develop confidence in their leadership skills.

The sessions where we have a lot more freedom are the most enjoyable for both the [Team Leaders] and the students. Some structure is obviously needed to make the students feel like they're gaining tangible skills; however, having freedom to take things in our own direction allows us to personalize the session to our students and to suit our own strengths. It also helps us have more fun and be creative! (NCM \#19)

\section{Discussion: Examining Benefits Between Peer Mentorship Groups}

Overall, it seems that both groups valued similar aspects of peer mentorship, with CMs most favourably valuing 
Table 1. Mentors' Perceptions of Benefits from Peer Mentorship

\begin{tabular}{lcc}
\hline Themes & Curricular peer mentors & Non-curricular peer mentors \\
\hline Leadership development & $23.8 \%$ & $66.6 \%$ \\
Building relations with mentees & $57.1 \%$ & $33.3 \%$ \\
Having a meaningful impact & $28.6 \%$ & $11.1 \%$ \\
Public speaking skills & $9.4 \%$ & $11.1 \%$ \\
Creative freedom & - & $22.2 \%$ \\
Feeling appreciated & $23.8 \%$ & - \\
Being able to teach and guide others & $19.0 \%$ & - \\
\hline
\end{tabular}

Data collected from open-ended survey questions. Percentages are relative to each respective mentorship group's total number of responses to the question on benefits perceived in mentorship.

student interaction, and NCMs most favourably valuing development of leadership skills. Both these benefits are in line with previous research on risks and benefits for mentors in peer mentorship (Colvin \& Ashman, 2010). This indicates that peer mentors may experience similar benefits in mentorship, regardless of program structure. The prioritization of leadership development over other benefits for NCMs is expected, as NCMs had many opportunities for structuring and leading their own mentor-led sessions. NCMs also cited "creative freedom" as one of the benefits gained from their peer mentorship program (see Table 1). While CMs had fewer opportunities than NCMs to design and lead their own mentor-led sessions, they did state that the most meaningful interactions with their mentees occurred during their mentor-led sessions, where mentors had at least some opportunity to plan and lead a few of their own tutorial sessions. Through engaging conversations, CMs shared past experiences from their postsecondary education with their mentees, allowing for a more personal connection to be formed between mentor and mentee. The differences in how CMs and NCMs valued their respective benefits could be attributed to the fact that the CMs had fewer opportunities to design and lead their own relative to NCMs. NCMs may have come to value a consistently developing leadership skillset because they were given more opportunity to do so, whereas CMs may have come to value the importance of student interaction more so than leadership development because they had fewer leadership opportunities to experience.

\section{Challenges Faced by Curricular Peer Men- tors}

Amongst CMs, the most prevalent challenge in working with mentees in a classroom setting was a lack of engagement (see Table 2). According to CMs' reports, mentees generally seemed uninterested and unwilling to participate in tutorial discussion. The lack of engagement stemmed from the fact that the MRIs were highly structured, time consuming and took away from any meaningful engagement between mentors and mentees. The prevalence of this challenge is reasonable, as we have discussed how CMs greatly valued forming relationships with their mentees during their mentorship experience.

I found it challenging to make those one on one connections during the structured MRI tutorials. I found it challenging to engage students during the MRI tutorial and found that there were mainly only 3 or 4 people answering questions. (CM \#11)...I've learned that mentors need to take a greater initiative to connect with students outside of the classroom, since the class content takes up much of the tutorials. (CM \#5)

CMs also struggled with their time commitment to the course. CMs wanted to be well prepared to answer questions from their mentees. Balancing peer mentorship in the classroom setting with other academic responsibilities made it difficult to prepare for tutorial sessions. It required scheduling with other peer mentors, which also brought about challenges in team dynamics if their peers were unavailable or uncooperative. 
We had to really be efficient with our time and work together as a team to plan out a successful tutorial because our students could tell when we were [unprepared]. Being a mentor and running a tutorial takes careful time and planning. If you want to have an impact on students through a course you have to put extra time into it. (CM \#17)

Finally, some CMs mentioned lack of autonomy and leadership as another issue during tutorial. CMs stated that MRIs hindered the opportunity to form meaningful connections between themselves and their mentees. Some CMs stated they would prefer to lead more sessions structured entirely on their own.

...I felt like during a lot of the weeks it was just me following through motions instead of being a leader, my favourite times were when I could create my own tutorials! I also found that the time commitment was a lot. (CM \#9)

\section{Challenges Faced by Non-Curricular Men- tors}

NCMs felt greatly constrained for time when working with mentees. High expectations were placed on NCMs, with some stating that they wished they could have reached out more to their students but could not due to other extracurricular responsibilities. Furthermore, NCMs sometimes felt demotivated when mentees did not commit time to weekly sessions, resulting in low student turnout. All this sometimes made it difficult to connect with students.

The expectations placed upon us were extremely high (when you are balancing more than one extracurric- ular activity alongside Spark), and it really taught me how to budget my time and still put time aside to be there for my students. (NCM \#19)

As with CMs, NCMs reported some difficulties in team dynamics with their partnered Team Leader. This pushed them to be more patient and adapt their mentoring styles for the sake of their mentees.

I found first semester my [partner] and I functioned on different wavelengths. I found it very hard to speak with them...I thought it was interesting just living through one of my first experiences of the kind. $\mathrm{Pa}$ tience is key and so is remembering that it isn't about you is important. Our goal was to have great sessions and we did! Though our relation could have been better. (NCM \#18)

\section{Discussion: Examining Challenges Between Peer Mentorship Groups}

As we saw when comparing the benefits between mentorship groups, a disparity in leadership opportunities became apparent when comparing the challenges faced between these groups, as only CMs cited lack of autonomy and leadership as a challenge in mentorship. However, both groups struggled in engaging with mentees, with CMs citing lack of student interest in tutorial, and NCMs citing lack of student commitment to sessions, resulting in low turnouts. For CMs, underwhelming student engagement appeared to stem primarily from overly-structured MRI sessions. For NCMs, a lack of student commitment may be an inherent drawback to working in a voluntary program, where a lack of commitment does not lead to any direct consequences. In contrast, a lack of mentee

Table 2. Mentors' Perceptions of Challenges in Peer Mentorship

\begin{tabular}{lcc}
\hline Themes & Curricular peer mentors & Non-curricular peer mentors \\
\hline Lack of engagement from mentees & $57.1 \%$ & $22.2 \%$ \\
Time management & $23.8 \%$ & $55.5 \%$ \\
Team dynamics & $9.5 \%$ & $22.2 \%$ \\
Lack of autonomy & $19.0 \%$ & - \\
Preparing for tutorial sessions & $9.5 \%$ & - \\
\hline
\end{tabular}

Data collected from open-ended survey questions. Percentages are relative to each respective mentorship group's total number of responses to the question on challenges perceived in mentorship. 
participation from a course-structured mentorship program could consequently affect the mentees' grades.

These challenges show that while both groups were displeased with the lack of opportunity to engage with mentees, the lack of engagement was for different reasons, likely tied to how each peer mentor perceived their role in mentorship. From their responses, NCMs demonstrate a strong perceived sense of responsibility in mentorship, which then leads to a greater sense of grief when their mentees do not commit. This strong sense of responsibility in leadership is supported by the fact that some NCMs cited team dynamics as one of their challenges to peer mentorship, indicating that NCMs struggle to adjust their personal leadership style when it contrasts with that of their partner. CMs, in contrast, did not have as many opportunities as NCMs to lead their own tutorials. They attributed the lack of engagement from their mentees to the MRI content, over which they did not have control. Thus, NCMs cited struggles in engagement with mentees due to over-expectations of both themselves and their mentees, while CMs cited the same struggle, but from MRI sessions minimizing the chance to personalize their tutorials and have meaningful interactions with their mentees.

\section{Mentors' Perceptions of Goal Setting in Peer Mentorship}

In this study, we were also interested in how implementing active goal setting in a peer mentorship program would influence mentors' perception of mentorship. CMs were required to set goals and keep track of their progress toward these goals as part of their mentorship program, whereas NCMs were given no specific instructions to do so. Both groups of peer mentors set a variety of personal goals, which fall under several themes and categories (see Table 3). Peer mentors were asked to rate the impact of goal setting on their mentorship experience on a 5-point Likert scale, measuring helpfulness of goals, and then to elaborate on their answer choices. We found slight differences in how CMs and NCMs perceived overall helpfulness of goal setting to their mentorship experience.

\section{Goal Setting for Curricular Peer Mentors}

Sixteen out of twenty-three (69.6\%) CMs rated the goal setting as a helpful activity in their mentorship develop- ment $6 / 23(26.1 \%)$ felt goal setting helped significantly and $10 / 23$ (43.5\%) felt it was somewhat helpful). When elaborating on their rating, these CMs stated that creating goals gave them the chance to fine-tune the direction of their mentorship and keep track of their progress. They believed that goal setting helped them self-reflect and plan ways to improve their mentoring strategy. It also motivated them to accomplish their duties during tutorial sessions, pushing their overall efforts in peer mentorship. "[Goal setting] provided some direction for my learning and development. Setting a goal is critical to achievement; if you don't have a milestone/outcome it's difficult to track progression over time." (CM \#19)

Not all comments were entirely positive. Even though these CMs rated the goal-setting activities as somewhat helpful, a few (4/10; 40\%) elaborated on their rating by saying that the goal setting activity felt restrictive:

Setting goals in this course taught me to set goals in almost everything that I did, and I learned the "goal-setting" skill, which has been very helpful to me in other aspects of my life. However, with respect to this course, I did not find the goal setting completely helpful because I was always trying to achieve my goals, although my goals kept changing throughout the semester. We were asked to set goals at the beginning of the term, but during the actual experience of this course, my goals formed and developed, and changed... (CM \#15)

Some CMs stated that goal setting neither helped nor hindered (4/23;17.4\%), or even somewhat hindered $(3 / 23 ; 13.0 \%)$ their mentorship experience. When elaborating on their rating, these CMs indicated that compulsory goal setting restricted their freedom. They stated that they felt overly pressured to focus on the goals they set at the beginning of the semester or that goal setting had little impact on their mentorship experience:

Although I really enjoyed the experience, I felt that focusing on achieving our goals hindered our ability to be free when deciding how the mentor-led tutorials. I felt that a lot of the time I focused on how I would collect evidence, even though it is more important to focus on the growth and development of our mentees. (CM \#18) 


\section{Goal Setting for Non-Curricular Peer Mentors}

While NCMs were not required to set goals as part of the Spark program, when asked about goal setting, some NCMs did state and elaborate on goals they set throughout their mentorship experience (see Table 3).

Five of the nine NCMs surveyed elaborated on their impressions of goal setting in peer mentorship, with three stating that it somewhat helped their experience, and two stating that it helped significantly (on a 5-point Likert scale, from hindered significantly to helped significantly). NCMs commented on how goal setting encouraged them to reflect over their work to target what they would like to improve upon in the future: "I think having goals sets an outlook and creates a plan of action that can get me excited and passionate about working hard" (NCM \#11). The remaining four NCMs had no comments and/or did not formally plan goals.

\section{Discussion: Examining Goal Setting Be- tween Peer Mentorship Groups}

While few CMs considered goal setting to be a hindrance, most believed that it at least somewhat helped shape their mentorship experience, with about a quarter of them praising it as a critical component in planning and tracking their progress, as well as motivating their overall efforts in peer mentorship. However, even amongst peer mentors that praised goal setting, some expressed frustration with its implementation. These frustrations reflect some of the challenges CMs cited in earlier survey questions. In the same way that MRIs limited CMs' opportunities to engage with their mentees, some CMs felt that goal setting restricted their ability to be flexible and spontaneous in peer mentorship. CMs thus appeared to desire more freedom in their mentorship experience.

Although NCMs were given no specific instructions or encouragement for setting goals, some NCMs did set

Table 3. Summary of Goals Set by Mentors

\begin{tabular}{|c|c|c|}
\hline \multirow{2}{*}{ Goals } & \multicolumn{2}{|c|}{ Count (\# and \%) } \\
\hline & CMs & NCMs \\
\hline Goals for self-development & $22 / 23(95.7 \%)$ & $7 / 9(77.8 \%)$ \\
\hline Learning theory of mentorship practice & $8(34.8 \%)$ & - \\
\hline Developing leadership skills & $6(26.1 \%)$ & - \\
\hline Developing communication skills & $4(17.4 \%)$ & - \\
\hline Achieving a high grade & $1(4.3 \%)$ & - \\
\hline Developing time management skills & $1(4.3 \%)$ & - \\
\hline Developing self-confidence & $1(4.3 \%)$ & - \\
\hline Personal growth/self-discovery & $1(4.3 \%)$ & $3(33.3 \%)$ \\
\hline Improving discussion facilitation & - & $2(22.2 \%)$ \\
\hline Improving interpersonal skills & - & $2(22.2 \%)$ \\
\hline Goals for helping others & $12 / 23(52.2 \%)$ & $5 / 9(55.6 \%)$ \\
\hline General helpfulness to others & $5(21.7 \%)$ & $2(22.2 \%)$ \\
\hline Forming relations with mentees & $4(17.4 \%)$ & - \\
\hline Being a role model & $3(13 \%)$ & $1(11.1 \%)$ \\
\hline Easing student transition & - & $2(22.2 \%)$ \\
\hline
\end{tabular}

Data collected from open-ended survey questions. Percentages are relative to each respective mentorship group's total number of responses to questions on the use of goal setting. 
their own goals and commented that these goals were at least somewhat helpful in guiding their mentorship experience. The fact that these NCMs set goals on their own accord, without being mandated to do so by their program, indicates that goal setting can be a self-motivated skill for some mentors. Indeed, the most effective leaders in a workplace tend to be ambitious and display a drive for personal achievement (Kirkpatrick \& Locke, 1991).

As previously mentioned, Biggs's conceptual framework of constructive alignment (2014) can be adapted and effectively applied to goal setting in these contexts. We learned, however, that allowing mentors flexibility to refine their goals throughout their mentorship role is an important aspect to encourage the mentors to gain the most from their goal-setting experience.

\section{General Discussion and Conclusions}

To the best of our knowledge, this is the first study comparing benefits and challenges in peer mentorship for mentors in the context of program structure and active goal setting at a postsecondary institution. Overall impressions of peer mentorship programs were positive for each respective group, with similar benefits of student interaction and development of leadership skills cited as the reasons that mentors' expectations of their respective programs were met. The only concerns came from CMs, where those whose expectations were not met stated that the course content was not influential in their mentorship experience. Concerns raised by CMs involved suggestions to update or refine the course content and assessment methods, as well as increase the number of leadership opportunities available to them.

\section{Limitations}

It should be noted that our data collection tool, the online survey, could not be reliably validated as we had created it ourselves to address our specific research questions. The nature of our data collection method, via email invitation, also introduces a self-selection bias, as peer mentors who were most vocal or enthusiastic about their experiences are the ones most likely to be responding to the survey. Finally, because all responses were collected anonymously without any ability to further communicate with the respondents, we were unable to follow-up with them for further elaboration of their responses.

Additionally, due to the limited response rate of NCMs $(9 / 40 ; 22.5 \%$ of respondents) relative to CMs (23/33; $69.7 \%$ of respondents), most comparisons in this study were limited to within-group comparisons. The low response rate from NCMs limited our ability to obtain elaborative responses representative of non-curricular peer mentorship programs, and future researchers may wish to further explore impressions of NCMs on peer mentorship in academia in greater detail.

It should also be noted that not all peer mentors came with similar background experiences in mentorship. Due to capped enrollment, all applicants for the curricular peer mentorship program went through a selection criterion before being enrolled as mentors, which asked about previous experiences in leadership and extra-curricular involvement. Peer mentors from the non-curricular Spark program went through a similar rigorous interview process before being admitted. It is likely that some peer mentors have had more experiences in leadership roles than their peers, which could influence their perceptions, challenges, and motivations to set goals in mentorship. For instance, peer mentors with more experience may be more motivated to mentor others entirely due to altruistic tendencies, rather than for personal gain (Aryee et al., 1996; Beltman \& Schaeben, 2012). For a clearer consensus on peer mentors' perceptions on program structure and goal setting, future studies should account for prior teaching, leadership, and mentorship experiences when assessing mentors' perceptions and approaches to peer mentorship.

\section{Implications and Future Directions}

Through this study, we have added to the literature on peer mentors' perceptions of mentorship and developed a deeper understanding of program structure and its influence on peer mentorship experiences. It has provided guidance on how to improve both course-based, structured peer mentorship programs and voluntary, student-led peer mentorship programs. It is important to consider the extent to which peer mentorship programs should guide mentors with structured learning, as well as the extent to which mentors should be left to explore their own mentoring style. It appears that many peer mentors in this study desired autonomy in conducting mentorship. However, this freedom may come with the consequence of increased burden of responsibility and 
time management. Future versions of this study should explore how much autonomy is given to mentors in peer mentorship programs and determine how it affects the evolution of the goals they set over the course of their mentorship experience.

Based on the results of this research, and other data collected through our survey, we suggest the following modifications to peer mentorship programs. For the curricular peer mentorship program, we suggest including more opportunities to develop mentor-led sessions and greater flexibility in adjusting and refining goals throughout the semester. For the non-curricular peer mentorship program, we suggest implementing earlier and more frequent team-building activities to better connect Team Leaders with each other. For both groups, it would be beneficial to develop methods and activities to better engage mentees that would encourage their ongoing involvement in their programs. To tackle this common struggle of dealing with uninterested or uncommitted mentees, course-structured programs may benefit from incorporating more meaningful individual interactions between mentors and mentees, and non-curricular or voluntary peer mentorship programs may benefit from familiarizing mentors and mentees to the level of commitment expected from each of them to ensure a fulfilling mentorship experience.

Finally, our findings on goal setting in peer mentorship show that mentors who value active goal setting may set goals themselves, regardless of whether a mentorship program encourages them to or not. For institutions seeking to incorporate active goal setting in their peer mentorship program, encouraging and educating mentors on the benefits of active goal setting may be more favourable than mandating its use. Additionally, allowing goals to evolve and change over the course of a mentorship experience may help reduce frustration among peer mentors that are unsure of exactly what they strive to achieve, or for those that change their mind about it after they have begun mentoring.

Future researchers should consider incorporating the mentees' perspectives on their peer mentors' performance and compare the effectiveness of mentorship between different types of peer mentorship programs. This could validate, or possibly invalidate, the mentors' perceptions on whether their peer mentorship program was successful for their mentees. A lack of coherence between mentors' and mentees' responses about the success of their peer mentorship program could indicate exactly which components of a structured peer mentorship program, such as the incentive for academic success, the inclusion of active goal setting, and the regular self-reflection sessions, may have been beneficial to the peer mentor, but uninfluential or possibly detrimental to the peer mentee.

\section{References}

Allen, T. D. (2003). Mentoring others: A dispositional and motivational approach. Journal of Vocational Behavior, 62(1), 134-154. https://doi.org/10.1016/ S0001-8791(02)00046-5

Aryee, S., Chay, Y. W., \& Chew, J. (1996). The motivation to mentor among managerial employees. Group \& Organization Management, 21, 261-277. https:// doi.org/10.1177/1059601196213002

Astin, A. (1975). Preventing students from.dropping out. Jossey-Bass.

Beltman, S., \& Schaeben, M. (2012). Institution-wide peer mentoring: Benefits for mentors. The International Journal of the First Year in Higher Education, 3(2), 33-44. https://espace.curtin.edu.au/handle/20.500.11937/13607

Biggs, J. (2014). Constructive alignment in university teaching. HERDSA Review of Higher Education, 1, 5-22. https://www.herdsa.org.au/herdsa-review-higher-education-vol-1/5-22

Biggs, J., \& Tang, C. (2003). Teaching for quality learning at university. SRHE.

Boyatzis, R. E., Smith, M. L., \& Blaize, N. (2006). Developing sustainable leaders through coaching and compassion. Academy of Management Learning \& Education, 5, 8-24. https://doi.org/10.5465/ amle.2006.20388381

Bryant, S. E., \& Terborg, J. R. (2008). Impact of peer mentor training on creating and sharing organizational knowledge. Journal of Managerial Issues, 20(1), 11-29. https://www.jstor.org/stable/40604592

Collings, R., Swanson, V., \& Watkins, R. (2014). The impact of peer mentoring on levels of student wellbeing, integration and retention: A controlled compar- 
ative evaluation of residential students in UK higher education. Higher Education, 68(6), 927-942. https://doi.org/10.1007/s10734-014-9752-y

Colvin, J. W., \& Ashman, M. (2010). Roles, risks, and benefits of peer mentoring relationships in higher education. Mentoring \& Tutoring: Partnership in Learning, 18(2), 121-134. https://doi. org/10.1080/13611261003678879

Crisp, G., Cruz, I. (2009). Mentoring college students: A critical review of the literature between 1990 and 2007. Research in Higher Education, 50(6), 525-545. https://doi.org/10.1007/s11162-009-9130-2

Du Preez, R., Steenkamp, L., \& Baard, R. S. (2013). An investigation into a peer module mentoring programme in economic and management sciences. International Business and Economics Research Journal, 12(10), 1225-1238. http://hdl.handle. net/10019.1/85448

Eby, L. T., \& Lockwood, A. (2005). Protegés' and mentors' reactions to participating in formal mentoring programs: A qualitative investigation. Journal of Vocational Behavior, 67(3), 441-458. https://doi. org/10.1016/j.jvb.2004.08.002

Eby, L. T., Durley, J. R., Evans, S. C., \& Ragins, R. R. (2006). The relationship between short-term mentoring benefits and long-term mentor outcomes. Journal of Vocational Behavior, 69(3), 424-444. https://doi.org/10.1016/j.jvb.2006.05.003

Ferrari, J. R. (2004). Mentors in life and at school: Impact on undergraduate protégé perceptions of university mission and values. Mentoring \& Tutoring: Partnership in Learning, 12(3), 295-305. https:/l doi.org/10.1080/030910042000275909

Freeman, D. (1998). Doing teacher research: From inquiry to understanding. Heinle \& Heinle.

Gibb, S. (1999). The usefulness of theory: A case study in evaluating formal mentoring schemes. Human Relations, 52(8), 1055-1075. https://doi. org/10.1023/A:1016983624755

Heirdsfield, A. M., Walker, S., Walsh, K., \& Wilss, L. (2008). Peer mentoring for first year teacher education students: The mentors' experience. Mentoring \& Tutoring: Partnership in Learning, 16(2), 109-124. https://doi.org/10.1080/13611260801916135

Jacobi, M. (1991). Mentoring and undergraduate academic success: A literature review. Review of Educational Research, 61(4), 505-532. https://doi. org/10.3102/00346543061004505

James, J. M., Rayner, A., \& Bruno, J. (2015). Are you my mentor? New perspectives and research on informal mentorship. The Journal of Academic Librarianship, 41(5), 532-539. https://doi.org/10.1016/j.acalib.2015.07.009

Jann, B., \& Hinz, T. (2016). Research question and design for survey research. The SAGE handbook of survey methodology, 105-121. https://dx.doi. org/10.4135/9781473957893.n9

Kirkpatrick, S. A., \& Locke, E. A. (1991). Leadership: Do traits matter? The Executive, 5(2), 48-60. https:/l doi.org/10.5465/ame.1991.4274679

Komarraju, M., \& Nadler, D. (2013). Self-efficacy and academic achievement: Why do implicit beliefs, goals, and effort regulation matter? Learning and Individual Differences, 25, 67-72. https://doi.org/10.1016/j. lindif.2013.01.005

Leidenfrost, B., Strassnig, B., Schütz, M., Carbon, C. C., \& Schabmann, A. (2014). The impact of peer mentoring on mentee academic performance: Is any mentoring style better than no mentoring at all? International Journal of Teaching and Learning in Higher Education, 26(1), 102-111. https://eric. ed.gov/?id=EJ1043041

Lincoln, Y. S., \& Guba, E. G. (1985). Naturalistic inquiry. Sage

Locke, E. A., \& Latham, G. P. (2002). Building a practically useful theory of goal setting and task motivation: A 35-year odyssey. American Psychologist, 57(9), 705-717. https://doi.org/10.1037/0003$\underline{066 \times .57 .9 .705}$

Martin, A. J., \& Elliot, A. J. (2016). The role of personal best (PB) goal setting in students' academic achievement gains. Learning and Individual Differences, 45, 222-227. https://doi.org/10.1016/j. lindif.2015.12.014

McKenzie, K., \& Schweitzer, R. (2001). Who succeeds 
at university? Factors predicting academic performance in first year Australian university students. Higher Education Research \& Development, 20(1), 21-33. https://doi.org/10.1080/07924360120043621

McLean, M. (2004). Does the curriculum matter in peer mentoring? From mentee to mentor in problem-based learning: A unique case study. Mentoring and Tutoring, 12(2), 173-188. https://doi. org/10.1080/1361126042000239929

Neuman, W. L. (2000). Social research methods: Qualitative and quantitative approaches (4th ed.). Allyn \& Bacon.

Parise, M. R., \& Forret, M. L. (2008). Formal mentoring programs: The relationship of program design and support to mentors' perceptions of benefits and costs. Journal of Vocational Behavior, 72(2), 225-240. https://doi.org/10.1016/j.jvb.2007.10.011

Pugliese, T., Bolton, T., Jones, G., Roma, G., Cipkar, S., Rabie, R. (2015). Evaluating the effects of the Faculty of Arts and Social Sciences mentor program. Higher Education Quality Council of Ontario. http:// www.heqco.ca/SiteCollectionDocuments/FASS $\% 20$ Peer\%20Mentor\%20ENG.pdf

Rodger, S., \& Tremblay, P. (2003). The effects of a peer mentoring program on academic success among first year university students. Canadian Journal of Higher Education, 33(3), 1-18. http://journals.sfu.cal cjhe/index.php/cihe/article/view/183438/183391

Quesnel, M., King, J., Guilcher, S., \& Evans, C. (2012). The knowledge, attitudes, and practices of Canadian master of physical therapy students regarding peer mentorship. Physiotherapy Canada, 64(1), 65-76. https://doi.org/10.3138/ptc.2011-02

Salinitri, G. (2005). The effects of formal mentoring on the retention rates for first-year, low achieving students. Canadian Journal of Education, 28(4), 853-873. https://doi.org/10.2307/4126458

Scandura, T. A., \& Williams, E. A. (2002). Formal mentoring: The promise and the precipice. In C. L. Cooper \& R. J. Burke (Eds.), The new world of work: Challenges and opportunities (pp. 49-74). Blackwell.

Sorrentino, D. M. (2006). The SEEK mentoring program: An application of the goal-setting theory.
Journal of College Student Retention: Research, Theory \& Practice, 8(2), 241-250. https://doi. org/10.2190/7D9T-D30Y-N9T0-8DWL

Tinto, V. (1975). Dropout from higher education: A theoretical synthesis of recent research. Review of Educational Research, 45(1), 89-125. https://doi. org/10.3102/00346543045001089

Tinto, V. (1997). Classrooms as communities: Exploring the educational character of student persistence. The Journal of Higher Education, 68(6), 599-623. https://doi.org/10.2307/2959965

Trochim, W. M., \& Donnelly, J. P. (2007). The research methods knowledge base. Thomson.

Venezia, A., \& Jaeger, L. (2013). Transitions from high school to college. The Future of Children, 23(1), 117-136. https://www.jstor.org/stable/23409491

Yomtov, D., Plunkett, S. W., Efrat, R., \& Marin, A. G. (2017). Can peer mentors improve firstyear experiences of university students? Journal of College Student Retention: Research, Theory \& Practice, 19(1), 25-44. https://doi. org/ $/ 10.1177 / 1521025115611398$

Zachary, L. J., \& Fischler, L. A. (2011). Begin with the end in mind: The goal-driven mentoring relationship. Training and Development, 65(1), 50-53. https:/l www.td.org/magazines/td-magazine/begin-with-theend-in-mind-the-goal-driven-mentoring-relationship

Zimmerman, B. J., Bandura, A., \& Martinez-Pons, M. (1992). Self-motivation for academic attainment: The role of self-efficacy beliefs and personal goal setting. American Educational Research Journal, 29(3), 663-676. https://doi. org/10.3102/00028312029003663

\section{Contact Information}

Zeeshan Haqqee

z.haqqee@gmail.com 